\title{
A multi-center, Phase II trial of nab-paclitaxel and gemcitabine in patients with non-small-cell lung cancer previously treated with platinum-based chemotherapy
}

This article was published in the following Dove Press journal:

Cancer Management and Research

\author{
Motoko Tachihara' \\ Tatsunori Kiriu' \\ Akito Hata ${ }^{2}$ \\ Yukihisa Hatakeyama ${ }^{3}$ \\ Kyosuke Nakata' \\ Tatsuya Nagano' \\ Masatsugu Yamamoto' \\ Kazuyuki Kobayashi ${ }^{1}$ \\ Hisashi Ohnishi ${ }^{3}$ \\ Nobuyuki Katakami ${ }^{2}$ \\ Yoshihiro Nishimura' \\ 'Division of Respiratory Medicine, \\ Department of Internal Medicine, Kobe \\ University Graduate School of Medicine, \\ Kobe, Hyogo 650-0017, Japan; \\ ${ }^{2}$ Department of Medical Oncology, Kobe \\ City Medical Center General Hospital, \\ Kobe, Hyogo 650-0047, Japan; \\ ${ }^{3}$ Department of Respiratory Medicine, \\ Akashi Medical Center, Akashi, Hyogo \\ 674-0063, Japan
}

Background: Nanoparticle albumin-bound paclitaxel (nab-PTX) plus gemcitabine (GEM) significantly improved overall survival in patients with metastatic pancreatic adenocarcinoma. Anti-tumor synergy between GEM and nab-PTX was recently demonstrated in a mouse model. We planned to assess the efficacy and safety of the combination of nab-PTX + GEM in patients with non-small-cell lung cancer (NSCLC) previously treated with platinum-based chemotherapy.

Methods: Patients with advanced NSCLC with progressive disease after platinum-based chemotherapy, an Eastern Cooperative Oncology Group (ECOG) performance status (PS) of 0 or 1 , and adequate kidney, liver and bone marrow function were eligible. Treatment consisted of nab-PTX $\left(100 \mathrm{mg} / \mathrm{m}^{2}\right)+$ GEM $\left(1000 \mathrm{mg} / \mathrm{m}^{2}\right)$ on days 1 and 8 of each 3 -week cycle until progression disease or unacceptable toxicity occurred. The primary endpoint was progression-free survival (PFS).

Results: Of the 28 patients enrolled, all were evaluable for response and toxicity. The median age was 68 years (range 47-79), and 23 were male and 5 female. The histologic subtypes were: adenocarcinoma in 19 patients, and squamous cell carcinoma in 9 patients. Seventeen patients had ECOG PS 1 and 11 patients had PS 0 . Twenty-four patients were second line and 4 patients were third line. The median number of cycles administered was 4 (range 1-10). The overall response rate was $17.9 \%$. The disease control rate was $67.9 \%$. The median progression-free survival was 3.1 months $(95 \%$ confidence interval $[\mathrm{CI}]=1.6-4.1)$. Adverse events were generally tolerable except grade 3 interstitial pneumonia with in 4 patients $(14.3 \%)$.

Conclusion: The efficacy of nab-PTX in combination with GEM in advanced second or third-line NSCLC patients was limited and the frequent occurrence of interstitial pneumonia was unacceptable.

Keywords: nab-paclitaxel, gemcitabine, non-small-cell lung cancer

\section{Introduction}

Recent progress in the treatment of advanced non-small cell lung cancer (NSCLC) has been remarkable. The development of immunotherapy resulted in a paradigm shift in NSCLC therapy. ${ }^{1-3}$ Now, platinum-doublet plus immune checkpoint inhibitors (ICIs) therapy is standard in the first-line therapy for patients with advanced NSCLC. But, probably most of the patients will become worse and need to have next chemotherapy. In the second-line therapy, cytotoxic chemotherapy is still
Correspondence: Motoko Tachihara Division of Respiratory Medicine, Kobe University Graduate School of Medicine,

7-5-I, Kusunoki-Cho, Chuo-Ku, Kobecity, Kobe-city 650-00I7, Japan

Tel +8I 783825660

Fax +8I 783825661

Emailmt03|8@med.kobe-u.ac.jp 
considered a key treatment for patients with advanced NSCLC. And even if disease progression does occur, many patients will still have a good performance status (PS) and can be considered for further active cytotoxic treatment. Docetaxel (DTX) plus ramucirumab (RAM) is one of second-line standard therapy, but some patients cannot receive RAM therapy because it is not adapted for RAM use. ${ }^{4}$

An albumin-bound formulation of PTX, nanoparticle albumin-bound paclitaxel (nab-PTX), can be administered more safely and with higher efficacy than solvent-based paclitaxel (sb-PTX). ${ }^{5}$ It is superior to sb-PTX because it can be administered to patients who are hypersensitive to solvents or alcohol, and it allows for shorter infusion times without necessitating steroid prophylaxis. Nab-PTX and CBDCA (nab-PC group) demonstrated a significantly higher ORR than PTX and CBDCA (sb-PC group) (33\% vs 25\%) in a Phase III trial in advanced NSCLC. ${ }^{6}$ In addition, a safety profile of nab-PTX was well tolerated. The nab-PC regimen produced less severe neuropathy, neutropenia, myalgia, and arthralgia compared with sb-PC group.

Recently, in patients with metastatic pancreatic adenocarcinoma, nab-PTX plus gemcitabine (GEM) was shown to significantly improve overall survival, although GEM has been the standard first-line treatment since $1997 .^{7}$ Moreover, the significant activity and favorable toxicity profile of the nab-PTX plus GEM combination was documented in patients with metastatic breast cancer. ${ }^{8}$

To study the efficacy and safety of nab-PTX plus GEM combination therapy for advanced NSCLC, we conducted a multi-center Phase II trial of nab-paclitaxel $\left(100 \mathrm{mg} / \mathrm{m}^{2}\right)+$ gemcitabine $\left(1000 \mathrm{mg} / \mathrm{m}^{2}\right)$ on days 1 and 8 of each 3 -week cycle for NSCLC patients who had been treated previously with platinum-based chemotherapy.

\section{Materials and methods}

\section{Patients and treatment}

Patients with advanced NSCLC with progressive disease after platinum-based chemotherapy, and an Eastern Cooperative Oncology Group (ECOG) PS of 0-1, as well as adequate kidney, liver and bone marrow function were eligible. Patients were also required to have measurable legions as defined by the Response Evaluation Criteria in Solid Tumors (RECIST) version 1.1. Key exclusion criteria were: previous treatment with nab-PTX, PTX or GEM; interstitial pneumonia recognized on chest-computed tomography (CT) scan. Treatment consisted of nab-paclitaxel $\left(100 \mathrm{mg} / \mathrm{m}^{2}\right)+$ gemcitabine $\left(1000 \mathrm{mg} / \mathrm{m}^{2}\right)$ on days 1 and 8 of each 3-week cycle until progression disease or unacceptable toxicity occurred, as assessed by the investigator.

Before enrollment, this study was approved by the ethics committee of Kobe University and each institution as a multicenter Phase II trial. The trial has been registered under University Medical Hospital Information Network (UMIN) Clinical Trials Registry Identifier UMIN 000017010. The protocol was approved through institutional ethical review boards each of the participating institutes, and all patients were provided written informed consent before treatment. The study was conducted in accordance with the ethical principles in the Declaration of Helsinki.

\section{Clinical analyses}

The primary endpoint was progression-free survival (PFS). Overall response (ORR), the disease control ratio (DCR), overall survival (OS) and adverse events also were evaluated as secondary endpoints. CT scans of the chest and the abdomen, and magnetic resonance imaging (MRI) studies or CT scans of the brain, and positron emission tomography (PET)-CT studies were performed for tumor assessment within 28 days of initiation of the study treatment. Tumor measurements were assessed with CT scans. CT scans were repeated with every 2 cycles until PD. Tumor assessments were done at baseline, then every 2 cycles until PD. Objective tumor responses were based on the RECIST version1.1. Toxicity evaluations were based on the National Cancer Institute Common Toxicity Criteria (NCI-CTC) version 4.0.

\section{Statistical analyses}

The study was designed as a prospective, multicenter, singlearm Phase II study. In light of the previous data, we assumed that PFS of 4.0 months in eligible patients would indicate potential usefulness, while PFS of 2.0 months would be the lower limit. A total of 25 assessable patients were required with one-sided significance level of $5 \%$ and power of $80 \%$. Taking ineligible patients into account, the sample size was set at 28. PFS and OS were analyzed using Kaplan-Meier method to estimate the median points with $95 \%$ CIs. Objective RR and DCR rates were calculated. All statistical analyses were performed using EZR (Saitama Medical Center, Jichi Medical University, Saitama, Japan, version 1.37), which is a graphical user interface for $\mathrm{R}$ (The $\mathrm{R}$ Foundation for Statistical Computing, Vienna, Austria, version 3.3.2). ${ }^{9}$ 


\section{Results}

From May 2015 to May 2017, a total of 28 patients from 3 institutions were enrolled in the study, and all of these subjects were evaluated for their therapeutic responses and drug toxicity. Baseline characteristics of the subjects are summarized in Table 1 . The median age was 68 years (range 47-79 years), 23 subjects (82.1\%) were male, and $17(60.7 \%)$ had a PS of 1 . The histopathology subtypes diagnosed included 19 adenocarcinomas (67.9\%) and 9 squamous cell carcinomas (32.1\%). Twenty-four patients $(85.7 \%)$ were given second-line treatment and $4(14.3 \%)$ were given third-line treatment.

The median number of cycles administered was 4 (range 1-10). The median follow-up time was 9.5 months (range 2.0-22.6 months). The overall response rate was $17.9 \%$

Table I Patient characteristics

\begin{tabular}{|c|c|c|}
\hline \multicolumn{2}{|c|}{ Patient characteristics } & \multirow{2}{*}{$\begin{array}{l}\text { Total number } \\
=\mathbf{2 8}\end{array}$} \\
\hline Age (median, range) & & \\
\hline Sex & $\begin{array}{l}\text { Female } \\
\text { Male }\end{array}$ & $\begin{array}{l}5(18 \%) \\
23(82 \%)\end{array}$ \\
\hline ECOG PS & $\begin{array}{l}0 \\
1\end{array}$ & $\begin{array}{l}\text { II (39.2\%) } \\
17(75.6 \%)\end{array}$ \\
\hline Smoking history & $\begin{array}{l}\text { Never smoker } \\
\text { Current or ex- } \\
\text { smoker }\end{array}$ & $\begin{array}{l}5(18 \%) \\
23(82 \%)\end{array}$ \\
\hline Histology & $\begin{array}{l}\text { Adenocarcinoma } \\
\text { Squamous cell } \\
\text { carcinoma }\end{array}$ & $\begin{array}{l}19(68 \%) \\
9(32 \%)\end{array}$ \\
\hline Clinical stage & $\begin{array}{l}\text { Stage IIIA } \\
\text { Stage IIIB } \\
\text { Stage IV } \\
\text { Postoperative } \\
\text { recurrence }\end{array}$ & $\begin{array}{l}1(4 \%) \\
5(18 \%) \\
18(64 \%) \\
4(14 \%)\end{array}$ \\
\hline EGFR mutation status & $\begin{array}{l}\text { Deletion in exon } 19 \\
\text { Exon } 21 \text { L858R } \\
\text { Wild-type/Unknown }\end{array}$ & $\begin{array}{l}5(18 \%) \\
3(11 \%) \\
18 / 2(64 \% / 7 \%)\end{array}$ \\
\hline $\begin{array}{l}\text { Number of prior } \\
\text { regimens }\end{array}$ & $\begin{array}{l}\text { I regimen } \\
2 \text { regimens }\end{array}$ & $\begin{array}{l}24(86 \%) \\
4(14 \%)\end{array}$ \\
\hline Prior chemotherapy & $\begin{array}{l}\text { CDDP + VNR } \\
\text { CDDP + PEM } \pm \text { BEV } \\
\text { CDDP + S-I } \\
\text { CBDCA + PEM } \pm \\
\text { BEV } \\
\text { CBDCA + S-I } \\
\text { DTX }\end{array}$ & $\begin{array}{l}1(4 \%) \\
10(36 \%) \\
3(11 \%) \\
5(18 \%) \\
6(21 \%) \\
3(11 \%)\end{array}$ \\
\hline
\end{tabular}

(Table 2). The disease control rate was 67.9\%. Median progression-free survival was 3.1 months (95\% confidence interval $[\mathrm{CI}]=1.6-4.1$ ) (Figure 1A). The median overall survival was 11.7 months (95\% CI, 8.0-19.3 months) (Figure 1B).

The adverse events that occurred are shown in Table 3. Five subjects (17.9\%) had grade 4 neutropenia, 4 (14.3\%) had grade 3 anemia and $3(10.7 \%)$ had grade 3 thrombocytopenia, but none of the subjects developed febrile neutropenia. No treatment-related deaths occurred. Non-hematologic toxic effects included interstitial pneumonia (IP, grade 3) in 4 subjects (14.3\%), neuropathy (with grade 1$)$ in $2(7.1 \%)$ and infections (with grade 3 ) in 2 subjects $(7.1 \%)$.

\section{Discussion}

This Phase II study failed to show significant therapeutic efficacy by the combination nab-PTX with GEM as second- or third-line therapy in patients with advanced NSCLC. However, this is the first report of examination of the combination nab-PTX with GEM in NSCLC. Nonplatinum combinations had been considered as alternative regimens for those who cannot tolerate platinum-based chemotherapy in the first-line setting. ${ }^{10-12}$ Kosmidis et al showed that non-platinum combinations of PTX and GEM had similar efficacy and safety compared to platinum doublet chemotherapy (median time to progression; 6.3 months vs 6.1 months) and the toxicity profile was similar for both. Gillenwater et al also reported that weekly PTX and GEM was an active and well-tolerated combination for advanced NSCLC in first-line settings. ${ }^{13}$ Moreover, nab-PTX can be administered more safely and with higher efficacy than sb-PTX. ${ }^{5}$ Contrary to expectations, the PFS of this present study was similar to that of DTX monotherapy. ${ }^{14,15}$ Our study did not meet the primary endpoint. There might be a difference between first-line treatment and second- or third-line treatment. For example, PFS of DTX monotherapy was reported 5.5 months in first line ${ }^{16}$ and $2-2.5$ months in second line. ${ }^{14,15}$

Table 2 Tumor response

\begin{tabular}{|l|l|l|}
\hline Response & Number of patients & $\%$ \\
\hline CR & 0 & 0 \\
PR & 5 & 17.8 \\
SD & 14 & 50.0 \\
PD & 9 & 32.2 \\
RR & 5 & 17.8 \\
DCR & 19 & 67.9 \\
\hline
\end{tabular}

Abbreviations: RR, response rate; DCR, disease control rate. 

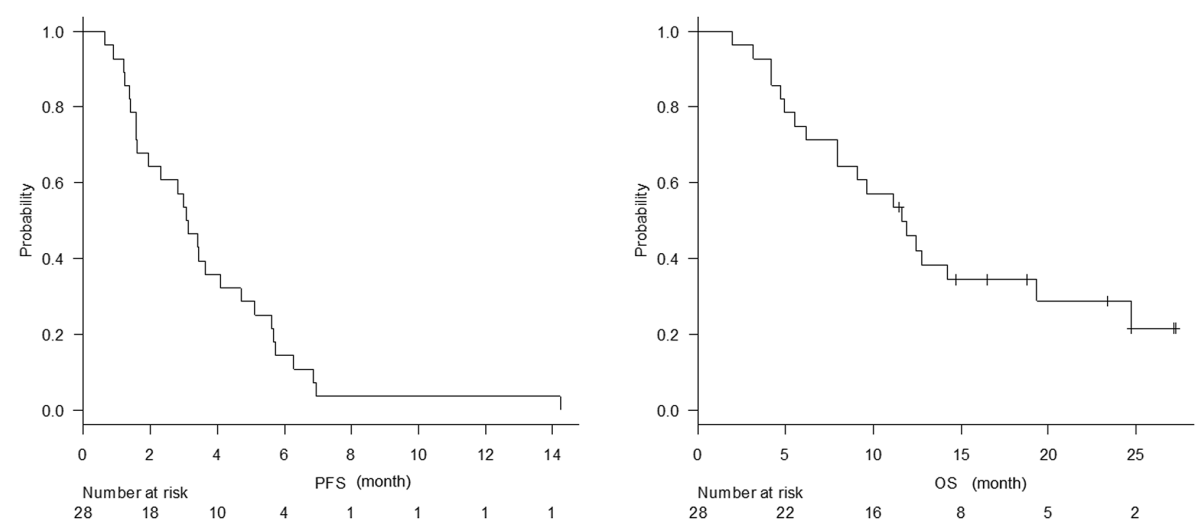

Figure I (A) Kaplan-Meier plots of progression-free survival. (B) Kaplan-Meier plots of overall survival.

Table 3 Adverse events

\begin{tabular}{|l|l|l|l|}
\hline Adverse event & All grades (\%) & G3 (\%) & G4 (\%) \\
\hline Leukopenia & 85.7 & 28.6 & 0 \\
Neutropenia & 71.4 & 28.6 & 17.9 \\
Anemia & 64.3 & 14.3 & 0 \\
Thrombocytopenia & 64.3 & 10.7 & 0 \\
Albumin decreased & 35.7 & 0 & 0 \\
ALT increased & 46.4 & 10.7 & 0 \\
AST increased & 42.9 & 7.1 & 0 \\
Total bilirubin increased & 14.3 & 0 & 0 \\
Creatinin increased & 14.3 & 0 & 0 \\
Interstitial pneumonia & 14.3 & 14.3 & 0 \\
Febrile neutropenia & 0 & 0 & 0 \\
Fatigue & 71.4 & 3.6 & 0 \\
Decreased appetite & 60.7 & 7.1 & 0 \\
Nausea & 25 & 3.6 & 0 \\
Vomiting & 10.7 & 3.6 & 0 \\
Diarrhea & 10.7 & 0 & 0 \\
Constipation & 42.9 & 0 & 0 \\
Fever & 50 & 0 & 0 \\
Infection & 17.9 & 7.1 & 0 \\
Peripheral neuropathy & 46.4 & 7.1 & 0 \\
Arthralgia & 21.4 & 0 & 0 \\
Mucositis/Stomatitis & 14.3 & 0 & 0 \\
Pruritus & 17.9 & 0 & 0 \\
Rash & 14.3 & 0 & 0 \\
Alopecia & 46.4 & 0 \\
Allergic reaction & 10.7 & 0 \\
\hline
\end{tabular}

In patients with pancreatic adenocarcinoma, this nabPTX plus GEM combination therapy has been taken in place of single GEM with significantly improved overall survival and significant activity in patients with metastatic breast cancer as well. ${ }^{7,8}$ There is also a possibility of a difference in effect in the various carcinomas.

Regarding safety, the incidence of IP was high. Severe IP with GEM is reported to occur in $0-5 \%$ of the patients with solid tumors and up to $13.8 \%$ in NSCLC pretreated patients. ${ }^{17}$ It was reported that combination nab-PTX + GEM treatment increases intratumoral GEM levels as a result of a marked decrease in the activity of primary GEM metabolizing enzymes. ${ }^{18}$ It might be suggested that IP appeared more frequently as the concentration of GEM increased. On the other hand, the prevalence of IP in pancreatic cancer patients treated with nab-PTX + GEM was reported as only 4\%. ${ }^{7}$ The varying incidence of IP in lung cancer and pancreatic cancer might reflect the presence of lung disorders or some inflammation such as emphysema in lung cancer patients.

In analysis of ICIs, although it was the examination of the patient to whom the ICIs were administered, pneumonitis occurred more frequently in patients with a history of asthma/chronic obstructive pulmonary disease than in those without $(5.4 \%$ vs $3.1 \%) .{ }^{19}$

We excluded patients whose IPs are recognized on chest CT scan. But, all four patients who developed IP had lung abnormalities, such as 4 findings like bronchitis and 1 severe emphysema. These abnormal findings in the background lung except lung cancer may suggest a possible risk factor for IP occurrence.

\section{Conclusion}

The efficacy of nab-PTX in combination with GEM in advanced second- or third-line NSCLC patients was limited and the high rate of development of interstitial pneumonia was unacceptable.

\section{Data availability}

The overview of this trial has been registered under UMIN Clinical Trials Registry Identifier (UMIN 000017010). 
Individual patient data are confidential and thus they cannot be made publicly available.

\section{Acknowledgments}

The authors would like to express our gratitude to all participating patients and investigators. The abstract of this paper was presented at the European Lung Cancer Conference 2018 (ELCC) as a poster presentation talk with interim findings. The poster's abstract was published in https://cslide.ctimeetingtech.com/elcc2018/atten $\mathrm{dee} / \mathrm{confcal} / \mathrm{print} /$ presentation/346.

\section{Disclosure}

Dr Nobuyuki Katakami reports personal fees from MSD, AstroZeneca, Ono Pharma, Taiho Pharma, Daiichi-Sankyo Pharma, Chugai Pharma, Eli Lilly, Boehringer-Ingelheim and Pfizer, outside the submitted work. Dr Yoshihiro Nishimura reports grants from Taiho Pharmaceutical Co., Ltd and Eli Lilly Japan K.K., during the conduct of the study. The authors report no other conflicts of interest in this work.

\section{References}

1. Gandhi L, Rodríguez-Abreu D, Gadgeel S, et al. Pembrolizumab plus chemotherapy in metastatic non-small-cell lung cancer. $N$ Engl J Med. 2018;378:2078-2092. doi:10.1056/NEJMoa1801005

2. Paz-Ares L, Luft A, Vicente D, et al. Pembrolizumab plus chemotherapy for squamous non-small-cell lung cancer. $N$ Engl $J$ Med. 2018;379:2040-2051. doi:10.1056/NEJMoa1810865

3. Socinski MA, Jotte RM, Cappuzzo F, et al. Atezolizumab for first-line treatment of metastatic nonsquamous NSCLC. $N$ Engl J Med. 2018;378:2288-2301. doi:10.1056/NEJMoa1716948

4. Garon EB, Ciuleanu TE, Arrieta O, et al. Ramucirumab plus docetaxel versus placebo plus docetaxel for second-line treatment of stage IV non-small-cell lung cancer after disease progression on platinum-based therapy (REVEL): a multicentre, double-blind, randomised phase 3 trial. Lancet. 2014;384:665-673. doi:10.1016/ S0140-6736(14)60845-X

5. Nyman DW, Campbell KJ, Hersh E, et al. Phase I and pharmacokinetics trial of ABI-007, a novel nanoparticle formulation of paclitaxel in patients with advanced nonhematologic malignancies. $J$ Clin Oncol. 2005;23:7785-7793. doi:10.1200/JCO.2004.00.6148

6. Socinski MA, Bondarenko I, Karaseva NA, et al. Weekly nab-paclitaxel in combination with carboplatin versus solvent-based paclitaxel plus carboplatin as first-line therapy in patients with advanced none small-cell lung cancer: final results of a phase III trial. J Clin Oncol. 2012;30:2055-2062. doi:10.1200/JCO.2011.39.5848
7. Von Hoff DD, Ervin T, Arena FP, et al. Increased survival in pancreatic cancer with nab-paclitaxel plus gemcitabine. $N$ Engl $J$ Med. 2013;369:1691-1703. doi:10.1056/NEJMoa1304369

8. Roy V, LaPlant BR, Gross GG, Bane CL, Palmieri FM. Phase II trial of weekly nab (nanoparticle albumin-bound)-paclitaxel (nab-paclitaxel) (Abraxane) in combination with gemcitabine in patients with metastatic breast cancer (N0531). Ann Oncol. 2009;20:449-453. doi:10.1093/annonc/mdn661

9. Kanda Y. Investigation of the freely available easy-to-use software "EZR" for medical statistics. Bone Marrow Transpl. 2012;48:452458. doi:10.1038/bmt.2012.244

10. Kosmidis P, Mylonakis N, Nicolaides C, et al. Paclitaxel plus carboplatin versus gemcitabine plus paclitaxel in advanced non-small-cell lung cancer: a phase III randomized trial. J Clin Oncol. 2002;20:3578-3585. doi:10.1200/JCO.2002.12.112

11. Kosmidis P, Kalofonos H, Christodoulou C, et al. Paclitaxel and gemcitabine versus carboplatin and gemcitabine in patients with advanced non-small-celllung cancer. A phase III study of the Hellenic Cooperative Oncology Group. Ann Oncol. 2008;19:115122. doi:10.1093/annonc/mdm 430

12. Georgoulias V, Papadakis E, Alexopoulos A, et al. Platinum-based and nonplatinum-based chemotherapy in advanced non-small-cell lung cancer: a randomized multicentre trial. Lancet. 2001;357:1478-1484. doi:10.1016/S0140-6736(00)04644-4

13. Gillenwater HH, Stinchcombe TE, Qaqish BF, et al. A phase II trial of weekly paclitaxel and gemctiabine infused at a constant rate in patients with advanced non-small cell lung cancer. Lung Cancer. 2005;47:413-419. doi:10.1016/j.lungcan.2004.08.009

14. Fossella FV, DeVore R, Kerr RN, et al. Randomized phase III trial of docetaxel versus vinorelbine or ifosfamide in patients with advanced non-small-cell lung cancer previously treated with platinum-containing chemotherapy regimens. The TAX 320 Non-Small Cell Lung Cancer Study Group. J Clin Oncol. 2000;18:2354-2362. doi:10.1200/JCO.2000.18.12.2354

15. Shepherd FA, Dancey J, Ramlau R, et al. Prospective randomized trial of docetaxel versus best supportive care in patients with non-small-cell lung cancer previously treated with platinum-based chemotherapy. $J$ Clin Oncol. 2000;18:2095-2103. doi:10.1200/JCO.2000.18.10.2095

16. Kudoh S, Takeda K, Nakagawa K, et al. Phase III study of docetaxel compared with vinorelbine in elderly patients with advanced nonsmall-cell lung cancer: results of the West Japan Thoracic Oncology Group Trial (WJTOG 9904). J Clin Oncol. 2006;24(22):3657-3663. doi:10.1200/JCO.2006.06.1044

17. Barlési F, Villani P, Doddoli C, et al. Gemcitabine-induced severe pulmonary toxicity. Fundam Clin Pharmacol. 2004;18:85-91.

18. Frese KK, Neesse A, Cook N, et al. nab-Paclitaxel potentiates gemcitabine activity by reducing cytidine deaminase levels in a mouse model of pancreatic cancer. Cancer Discov. 2012;2:260-269. doi:10.1158/2159-8290.CD-11-0242

19. Sul J, Blumenthal GM, Jiang X, et al. FDA approval summary: pembrolizumab for the treatment of patients with metastatic non-small cell lung cancer whose tumors express programmed death-ligand 1. Oncologist. 2016;21:643-650. doi:10.1634/theoncologist.2015-0498 


\section{Publish your work in this journal}

Cancer Management and Research is an international, peer-reviewed open access journal focusing on cancer research and the optimal use of preventative and integrated treatment interventions to achieve improved outcomes, enhanced survival and quality of life for the cancer patient.

The manuscript management system is completely online and includes a very quick and fair peer-review system, which is all easy to use. Visit http://www.dovepress.com/testimonials.php to read real quotes from published authors.
from:

Submit your manuscript here: https://www.dovepress.com/cancer-management-and-research-journal 